\title{
Forecasting Performance and Achieving Performance Indicators in High Stress and Seismically Active Mining Environments
}

\author{
D.A. Beck Beck Mining Engineering, Australia \\ P. Duplancic Argyle Exploratory Decline, Australia
}

\begin{abstract}
Most highly stressed and seismically active mines fail to account for the true costs of rock related hazards during early planning stages. The consequences of planning decisions are sometimes not understood, so are not accounted for in schedules or budgets, and this ultimately results in poor performance. Sometimes the lack of understanding of the mining environment during the planning phase actually results in poor mine plans that cause the undue levels of stress induced hazard.

This paper focuses on simple techniques, guidelines and analysis tools for use by site based engineers to assist in mine planning for seismically active, high deformation or highly stressed environments. The paper also discusses the impacts of stress hazards on production, analysis of stress and deformation data and the integration of analysis results to achieve resilient and sustainable designs.
\end{abstract}

\section{INTRODUCTION}

A progression towards ground stress being a major engineering concern is inevitable in most mines as the operating depth increases. Stress increases with depth but the rock strength does not.

Many mines have difficulty forecasting the effects of increasing stress with depth and in managing stress hazards such as rockbursts, and some of the tools used by consulting engineers are not readily available to mine sites. This results in a dependency on external assistance for analysis. However, day-by-day observations of developing conditions are not always apparent to the off-site engineers who will undertake the analysis and make many important mine planning decisions.

This paper presents some simple tools and concepts to better relate excavation performance seismic hazard to induced stresses and deformations. The relations developed can be used to improve forecasts of excavation performance.

\section{IMPACTS OF HIGH STRESS AND SEISMICITY ON SCHEDULES AND PRODUCTION}

In all mines, stress induced hazards are not unique and general performance should be predictable. Unfortunately, in many recent cases of mine under-performance, a major factor in the incorrect calculation of production rates was the failure to integrate the costs of changing stress conditions into economic models. Even when the stress environment is understood it is often too difficult to account for the cost of stress induced hazards when making planning decisions.

The problem is compounded by a lack of data and also by the pace of change in underground mines. Owing to rapid vertical advance rates and high stress gradients in many Australian mines, symptoms of developing problems often become apparent in the late stages of a mining panel or the late stages of mining on a level. By this stage, the development for the next mining stage is in place and it usually is too late to change the mining plan.

Rock mechanics performance indicators are frequently not being interpreted far enough in advance for mine planning purposes.

\subsection{Early Warning Signs}

Some typical warning signs of developing stress induced hazards are:

- changes in the observed stable dimension in pillars,

- a progressive increase in scat production from level to level or panel to panel,

- increased seismicity,

- increasing drilling difficulties, and

- an increased frequency of falls-of-ground; in this case just one to two "new" stress related fall mechanisms may indicate a change in the interaction between the mines typical excavations and the stress field.

In some mines where stress induced hazards have forced closure, some of these early warning signs were present but were ignored. Figure 1 shows a long section of a mine with an unplanned remnant central access pillar. At this mine, each successive level would be abandoned prior to completion owing to poor conditions and extreme seismic behavior in the access pillar. Despite repeated poor performance, the mine continued with central access to the orebody for several levels.

\subsection{Damage Progression}

\subsubsection{A common scenario}

In parts of Western Australia, where major principal stress gradients have been measured as high as $0.08 \mathrm{mPa} /$ vertical metre, the progression of stress problems in a rapidly vertically advancing mine can be extreme.

If the warning signs are not heeded or occur too quickly, the mine will not be prepared. The following is a common progression in a mine where the mining plan does not match the stress environment and so is unsustainable in the long term:

1. A mining panel regularly experiences previously unexperienced stress induced stability issues in stopes. Typically, mines respond with more or larger pillars and smaller stopes. The damage might be minor, but the recovery ratio falls owing to the larger pillars.

2. In addition to stope and pillar problems, a deeper mining panel starts to experience damage in development. Initially the damage in development 


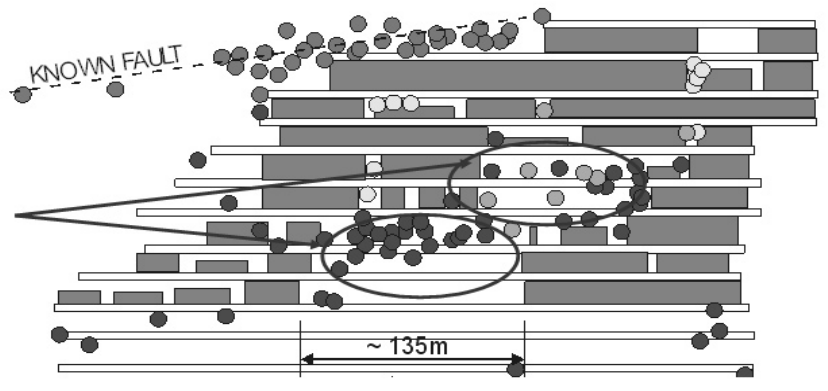

Events interpreted to be due to fault

Events associated with pillar failure

Events adjacent to production faces

Largest events (>1.0MLlrecorded occur in central pillar

FIG. 1 Long section of an example mine with a central access strategy showing the concentration of large $\left(>0.5 \mathrm{~m}_{\mathrm{L}}\right)$ seismic events lags production by several levels, or is tightly constrained to the advancing stoping front, or occurs only in the latest stages of production on a level. For example, the access to remnant pillars might be lost 1-2 levels above the producing levels.

3. The damage in development begins to catch up to the producing levels. Brows deteriorate, and hole damage and/or seismicity may start to become a problem. Where central access is employed, some of the production from the planned central pillar may be lost due to excessive deformation. This deformation may be seismic or aseismic.

4. Late stages of a closeout pillar may experience induced stresses such that access is lost before production is finished on a level. Support that is adequate to accommodate either large deformations or seismic conditions has not been installed due to lack of planning. This represents a new stage because unplanned ore loss has occurred. Alternatively, significant rehabilitation would be required and in extreme cases this can be unsafe.

5. At this stage, as an ore source has finished prematurely, it must be made up elsewhere. Deeper levels with the same geometry will not perform better, so the gap in the production schedule will grow. The most immediate problem in most mines is not the loss of ore reserves, but the depletion of the reserve of development in advance of production.

An example of a mine which showed this progression is shown in Figure 2, with each of the five stages shown.

This eventual progression is almost universal in mines with a high vertical advance and an inappropriate access methodology and sequence. Inadequate planning often results in too little time to respond to problems.

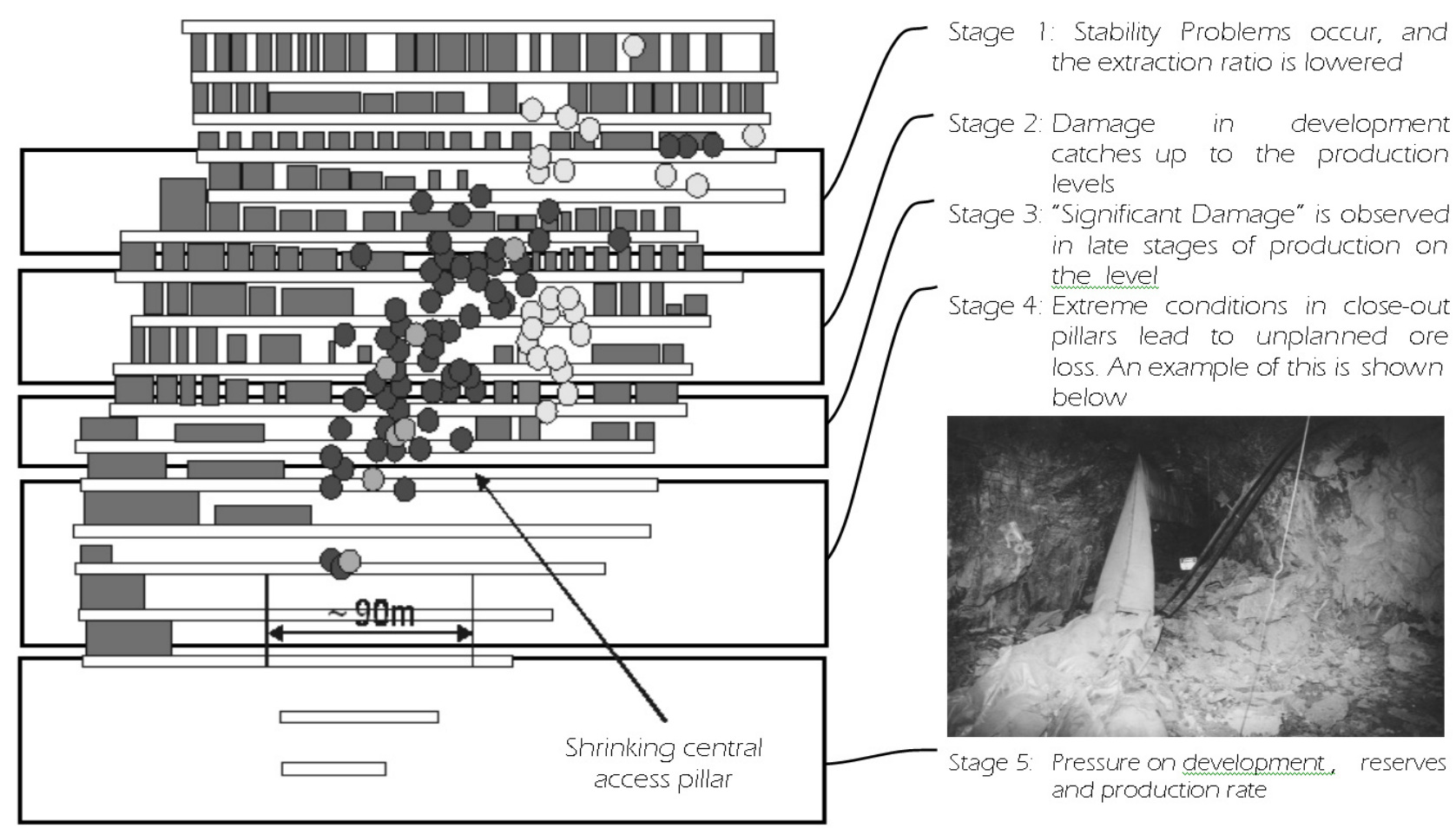

FIG. 2 Stages in the progression of stress related damage at an example mine 


\subsubsection{Mining with high pre-mining stress fields}

In high stress or at great depth, examples of sequences that have resulted in stress induced hazards in Australia are:

- central access sequences,

- mines with regular crown pillars, for example top down mines with overhand cut and fill, and

- open stoping mines where secondary extraction is not closely tied to primary extraction; in extreme cases continuous advance (pillar-less except for regional pillars) sequences are necessary.

Each of these example sequences can still be considered in high stress environments, but the potential that they may not be compatible with conditions should be carefully considered at the feasibility stage. The key requirement in planning is that actual, most likely performance should be evaluated, rather than a blind assumption that any problems will be manageable with minor changes or ground support.

\subsubsection{Lessons learned}

The lessons to be learned from the mines that have failed to manage the progression from low to high stress are:

1. That the progression from one scale of damage to another is inevitable with enough depth if ground support and the mining sequence and method are not appropriate.

2. Where effects of increasing stress are not considered, extraction ratios can be lower than planned and the schedule may be challenged. For most moderate to deep mines, it is worthwhile to undertake a mine scheduling exercise to determine the increases required in development rates to accommodate an unplanned loss of $10-30 \%$ of ore on each level without a reduction in tonnes produced.

3. A relatively common factor in unplanned, premature mine closure due to seismicity or stress hazards is that when an ore source is unexpectedly lost, there is insufficient development to enable new ore sources to be brought on line, and a production hole results.

4. With increasing depth, some sequences (for example central access) become unsustainable or problematic more frequently than others.

5. When designing access pillars, the goal must be to safely maintain sufficient stability for access for the required life of the level, as well as to maintain long term regional stability.

6. The most reliable sequences for managing stress in steeply dipping orebodies are continuous sequences with end access and stoping fronts shaped to interact favourably with the stress field. Typical favourable geometries are echelon or inclined mining fronts with disciplined lead and lag distances between production faces (brows). The leads and lags should be designed using numerical modelling or stoping trials to ensure that the progression of damage on each successively lower level is maintained at minimum possible levels. Diagrams of mining layouts with carefully constrained lead and lag distances are shown in Figures 3 and 4. In the example of Figure 4 , detailed numerical back analysis was used to determine damage criteria, which were in turn used to optimise the design.

7. Ground support must be adequate and installed before problems occur as the progression of damage on any level inside a closeout pillar can be rapid, particularly in rock exhibiting brittle behavior.

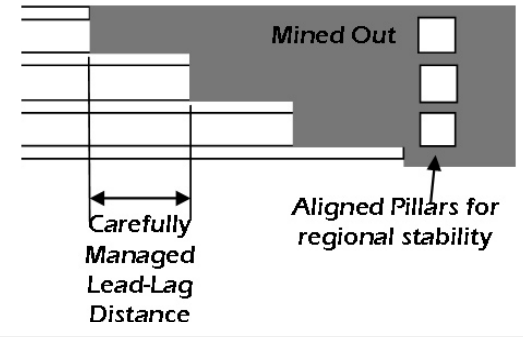

FIG. 3 Carefully managed lead-lag distances in a longitudinal orebody

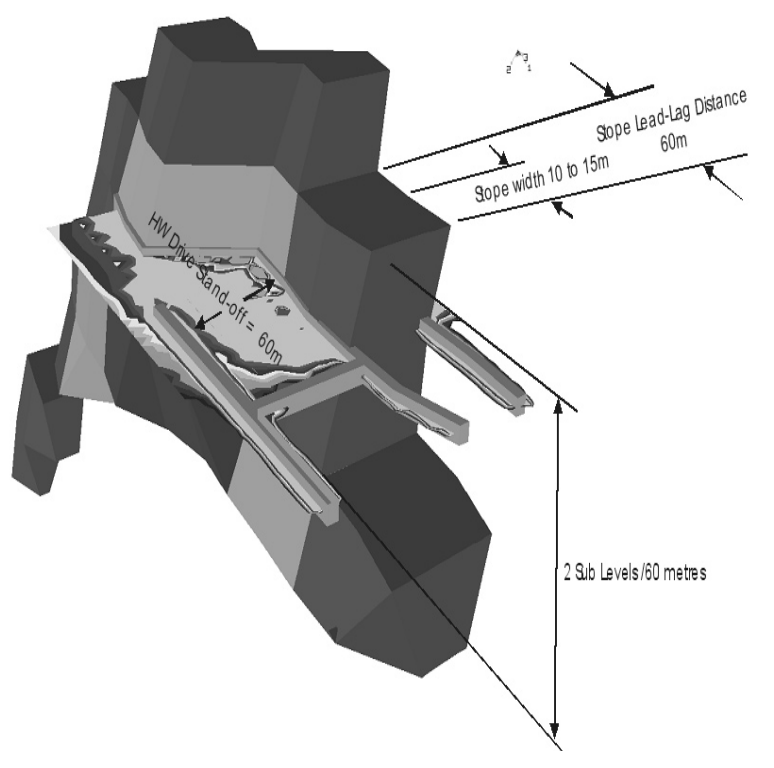

FIG. 4 Carefully managed lead-lag distances in a complex 3D orebody

8. At most small to medium sized Australian mines, ground support standards are not reviewed frequently enough to account for the rapid pace of the changes experienced with depth.

\section{ANALYSIS OF STRESS AND DAMAGE DATA USING ELASTIC MODELS}

Simple elastic boundary element modelling (BE) is time and cost effective and is the stress analysis most frequently available to the site based engineer for considering most of the aspects discussed above.

\subsection{Forecasting Performance using Boundary Element Elastic Models}

Although BE is probably the most frequently used method for analysis of stress effects in underground mines, the method does not forecast displacement very well and it assumes that rock material will behave elastically. That is, damage and seismicity due to over-stressing, yield or movement on structures isn't directly accounted for in the model.

This brings about some important considerations when forecasting damage potential using an elastic model in a seismically active or high deformation mine:

- Damaged areas don't "relax" in the model, that is, they continue to show high stress after they would have failed and would have long ceased to be able to carry so much stress.

- As the stress is not re-distributed from a failed region or in the vicinity of a damaged structure in the model, propagation of failure due to re-distributed stress and 
increased loads outside the failed region cannot be simulated (for example as occurs in a "domino" type pillar failure scenario).

- Late stage falls of ground, support failure, poor brow conditions and squeezing are examples of observed damage that are usually driven by deformation following some induced yield. The most obvious consequence of this is that de-stressing of ground that was previously shown to be beyond a yield condition in an elastic model results in worse hazard than if the elastic model were correct and the pre-failure integrity of the rockmass was maintained.

These points are important, but are not fatal flaws for the requirements of most studies if the operator is experienced. Generally, the following guidelines are used when interpreting elastic modelling results:

- Elastic models do not directly simulate the deformation of yielded ground, but it is generally accepted that decreasing confinement (usually modelled by minor principal stress $\sigma_{3}$ ) and increased major principal stress shown in an elastic model in a theoretically yielded region will result in worse post-yield deformations, as will ground that is shown to more greatly exceed the yield criterion.

- In other words, neither major principal stress nor confinement will show yield potential well - only a yield criterion can do this - but in an elastic model, for practical engineering purposes, the performance of the ground may be correlated with them even after the ground has been damaged.

- An example of a relation between $\sigma_{1}-\sigma_{3}$ and damage in a drive in Lac du Bonnet granite is shown in Figure 5 from Martin (1999), clearly showing the coincidence between failure, yield (microseismicity) and $\sigma_{1}-\sigma_{3}$. For most purposes, the extent by which ground is shown to exceed the yield criterion is assumed to correlate with worsening conditions and this is not a conservative assumption.

- The problem of stress not being re-distributed from failed regions in the model is usually accounted for in a calibrated or well-constructed model by assuming that the damage extent is underestimated, or by manually changing the properties of obviously overstressed areas, for example by removing from the model pillars that would have failed.

- When comparing alternate mining options on a mine-scale, a general and usually valid assumption is that the extent of yield is underestimated by a similar amount in each case. This means that even though the model is imprecise, alternative mining options can be compared. This assumption can be critically flawed when comparing widely disparate options, including comparisons of some sequences, or where energy considerations are as important as yield extent.

- Elastic BE models should never be used to analyse problems where displacement is the only performance indicator.

Problems with using elastic models for underground analysis usually occur when

i. the extent of yield is indicated to be very large,

ii. the models are relied upon to interpret very detailed phenomena, and

iii. there is a problem of large strain or when effects of gravity are important in influencing the failure mode.

In these cases, the model may be inadequate.

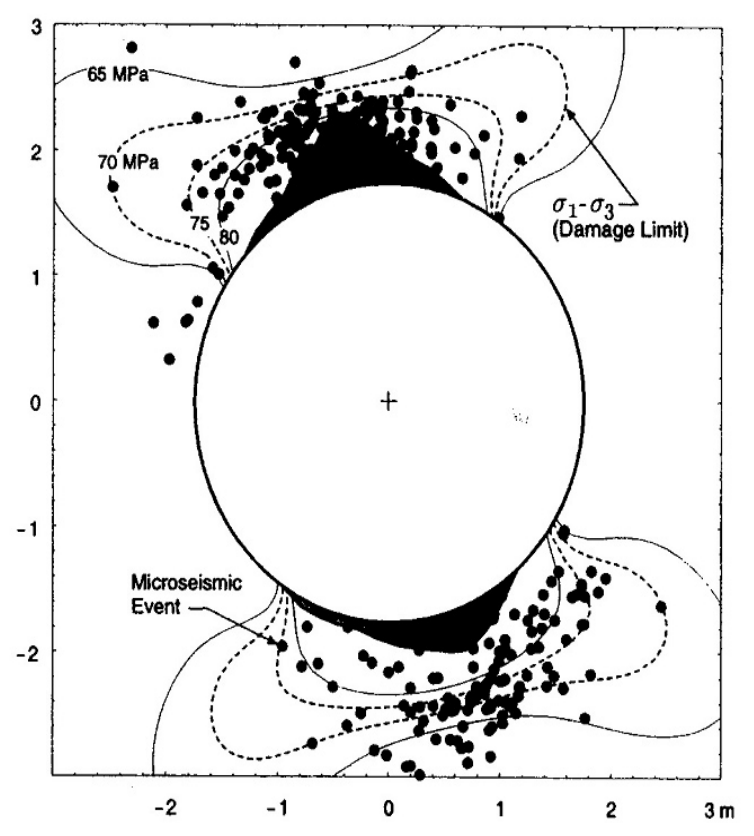

FIG. 5 Relation between $\sigma 1-\sigma 3$ and evidence of damage for a drive in lac du bonnet granite (Martin, 1999)

\subsubsection{Forecasting drive performance}

Calibration of a model to forecast damage levels allows prediction of likely conditions at depth, so that the mine plan can be optimised. If the impacts of poor ground conditions are understood, it is possible that performance estimates can be discounted in forecasts.

To facilitate transparency and understanding when calibrating damage in elastic BE models a damage scale is proposed known as the Common Damage Scale or CDS. A significant benefit is that the calibrated model properties can be more easily compared from mine to mine, because the performance indicators are common.

To minimise problems with the interpretation of damage levels, they are related directly to the actions required to maintain access to the drive. Damage was defined in this way because experience suggests that there is less deviation in opinions about required repairs than in opinions about the best way to describe damage. Use of the scale at several mines has shown that each of the classes of damage should be readily identifiable by all engineers and geologists with very little disagreement about damage classification.

The CDS is presented in Table 1. The damage data is collected by mapping damage in all relevant access development. The entire length of every drive is classified, including areas where no damage has occurred.

An example of damage mapping is shown in Figure 6, with "no damage", "moderate damage" and "significant damage" observed. Some examples of these classes of damage are shown in Figures 7, 8 and 9.

The precision implied by the firm damage definitions does not imply similar precision of any of the analysis. Ground that is forecast to experience one category of damage may easily experience another, and the clear definitions are only to assist in interpreting analysis. Generally, forecasts of ground damage should be limited to the minimum likely damage level. For example when reporting, the forecast would always say "minor damage or worse", "moderate damage or worse" etc. 


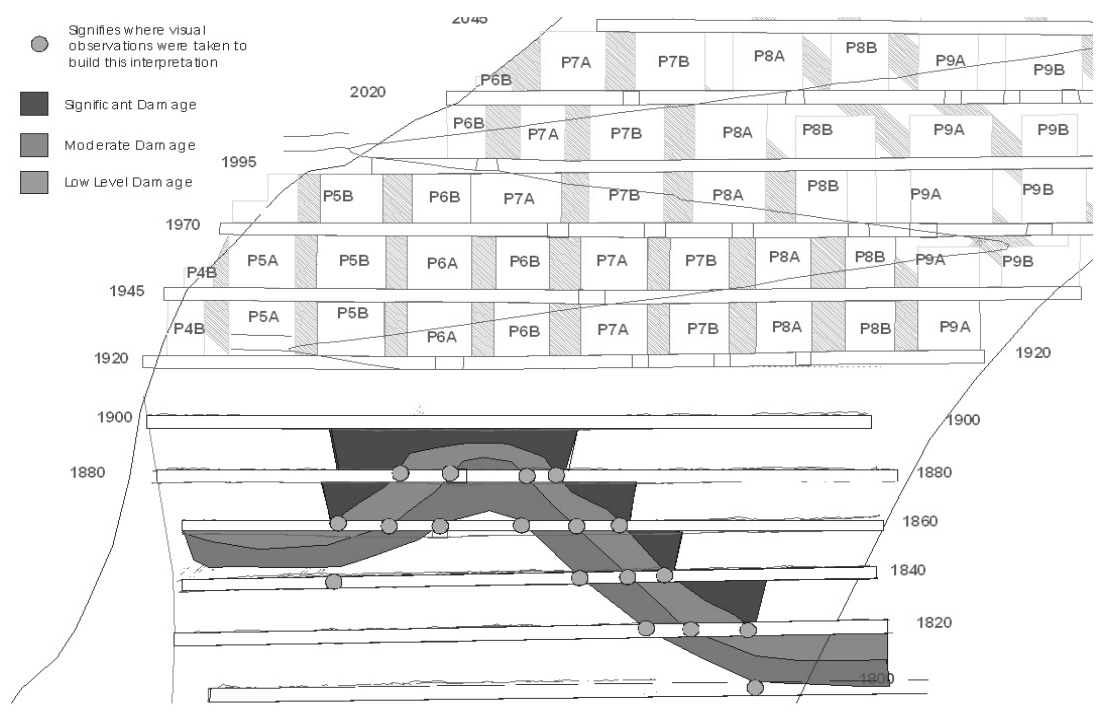

\section{FIG. 6 Example of damage mapping with hand drawn damage contours}

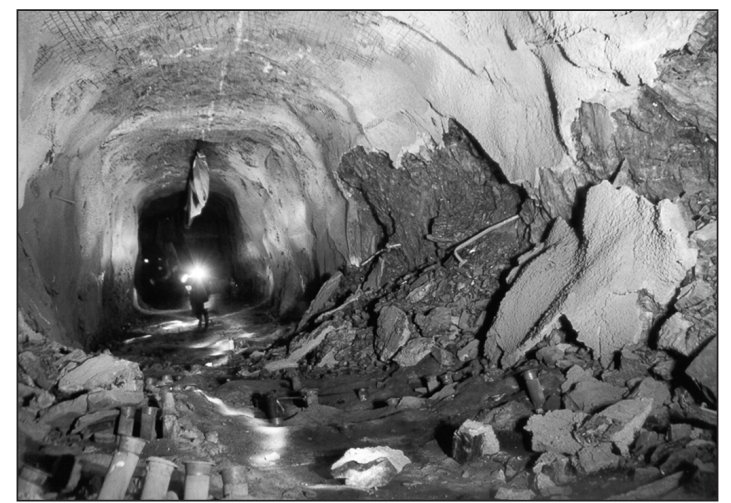

FIG. 7 Example of "significant" to "very significant" damage (Capes, 2003)

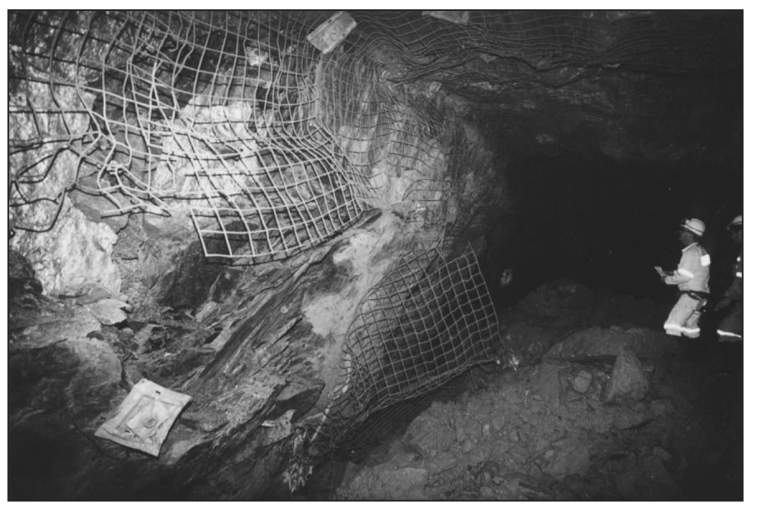

FIG. 8 Example of "moderate" to "significant" damage

After damage mapping is complete, the progression of damage from low levels of damage to more "significant" damage is then correlated with a model performance indicator.

For specific drive damage forecasts, there have been good results comparing damage levels to both Mohr-Coulomb Factor of Safety (Mohr-Coulomb FOS) and confinement. For FOS, the lowest value seen in the area of interest in all model

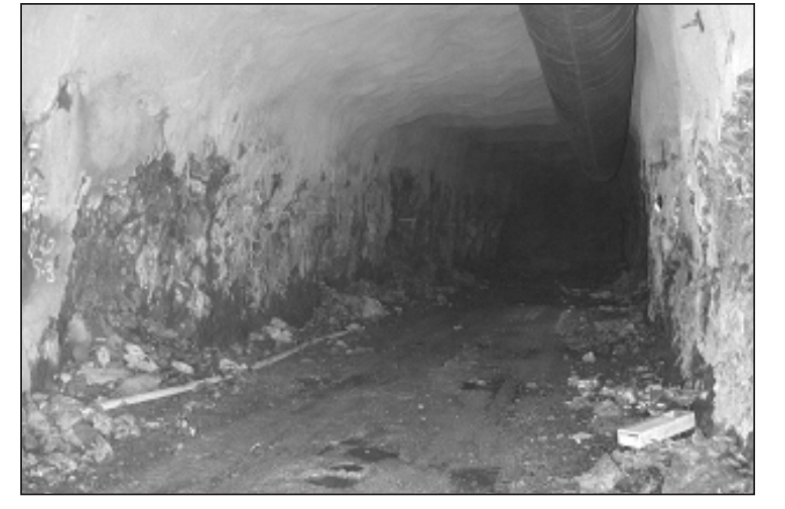

FIG. 9 Example of "minor" to "moderate" damage

steps is used owing to the elastic assumption of the model, and the confinement is the drop in minor principal stress $\left(\sigma_{3}\right)$ from the virgin condition.

The Mohr-Coulomb FOS can be defined in two ways, assuming that either $\sigma_{1}$ (Major Principal Stress) is driving the yield (FOS ${ }_{\mathrm{A}}$ in a Map3d model), or assuming that rising $\sigma_{1}$ and falling $\sigma_{3}$ are both important controls on yield (FOS ${ }_{C}$ in Map3d models) (Wiles, 2004).

Based on experience, the latter is more generic and is preferred where most damage follows "significant" nearby extraction (and therefore a loss in confinement).

Experience applying the damage scale for correlation with elastic model outputs at a number of mines has shown that when the model is calibrated such that an FOS of 1.0 approximates the onset of "moderate" conditions, the modelled rockmass compressive strength is $40-60 \%$ of the laboratory UCS. Friction angle is related closely to the rock type. 

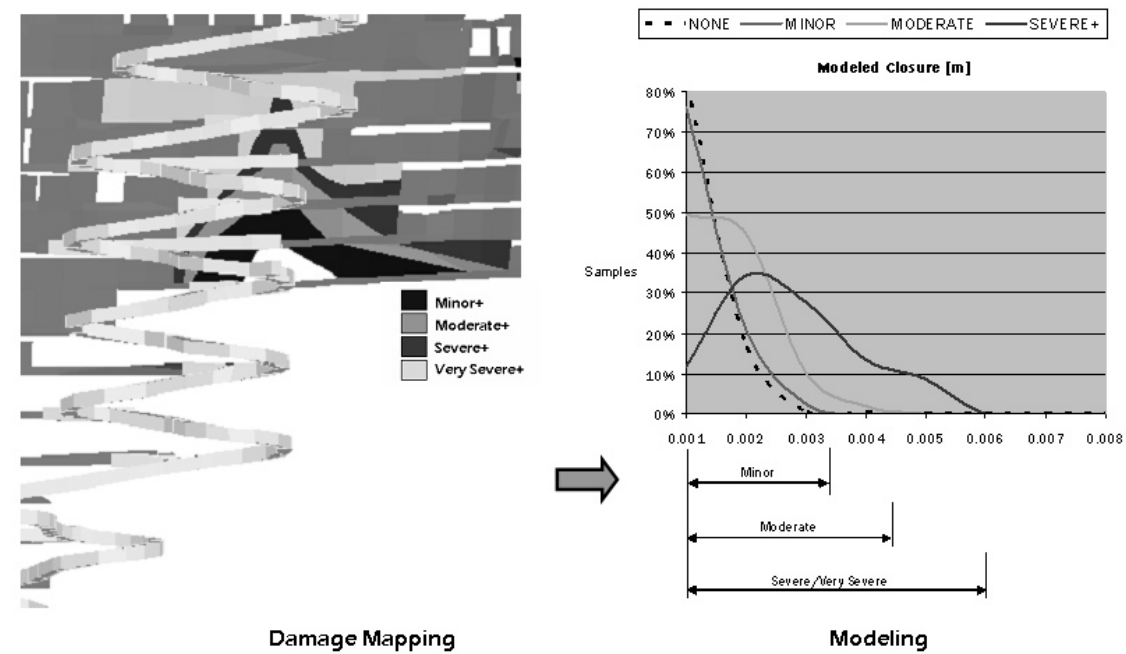

Damage Mapping

Modeling

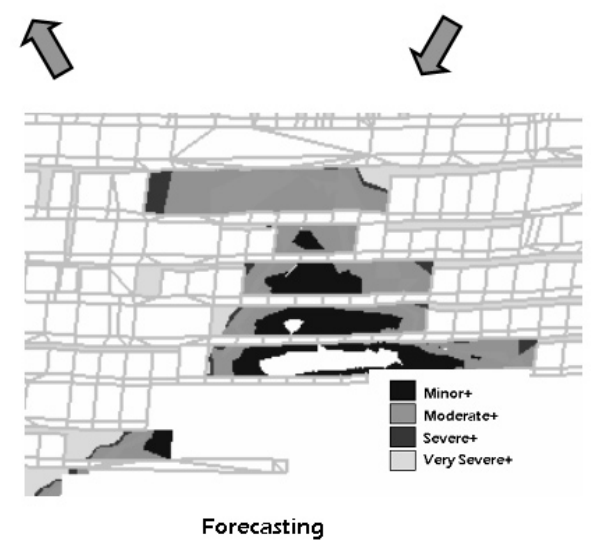

FIG. 10 Example of the damage mapping correlation process

TABLE 1 The Common Damage Scale (CDS)

\begin{tabular}{ll}
\hline Class & Description \\
\hline Very Significant & $\begin{array}{l}\text { Drive surface heavily deformed, drill holes } \\
\text { crushed, support visibly loaded. } \rightarrow \text { Substantial } \\
\text { rehabilitation required to prevent frequent falls } \\
\text { of ground }\end{array}$ \\
\hline Significant & $\begin{array}{l}\text { Any or all of: Buckling, dilation of existing } \\
\text { structure or induced fractures, failed corners } \\
\text { and brows, hole problems. Bulking of the } \\
\text { mesh is present in some areas. } \rightarrow \text { "Spot" } \\
\text { rehabilitation required to maintain access, } \\
\text { more substantial rehabilitation required for drill } \\
\text { and blast activity etc. Severe hole problems } \\
\text { develop }\end{array}$ \\
\hline Moderate & $\begin{array}{l}\text { Shearing on existing structure, visible yield. } \\
\text { Frequent scats in the mesh, or material may be } \\
\text { spalling under mesh. } \rightarrow \text { Rehabilitation required } \\
\text { only when intense activity will be undertaken } \\
\text { in the area (ie drill and blast). Drive still safe } \\
\text { for travel. Holes show more frequent signs of } \\
\text { damage, sometimes requiring re-drilling. }\end{array}$ \\
\hline Minor & $\begin{array}{l}\text { Minor signs of strain or displacement on } \\
\text { persistent structures, some occasional scats in } \\
\text { mesh. } \rightarrow \text { No rehabilitation required. }\end{array}$ \\
\hline None & $\begin{array}{l}\text { Blast damage/virgin stress damage only } \rightarrow \\
\text { Primary support controls drive surface }\end{array}$ \\
\hline &
\end{tabular}

If the scheme is used, it is recommended that the damage be mapped over many levels, and that the calibration be repeated every few months or following significant changes in geometry. This allows a wider range of environmental conditions to be sampled.

The more "snapshots" of damage at different times that are available for the calibration, the more confidence there can be in the model. Also, if the observations span a wide range of depths, there will be more confidence in forecasts of performance at greater depths, further ahead in the schedule.

An example of the process applied at one mine is shown in Figure 10. At this mines damage mapping, yield criteria, modelled closure on inelastic displacement discontinuity elements and seismicity were correlated quantitatively by discretising the mapped damage zones into sample grids. Results for model values were then plotted graphically.

Repetition of the process on a regular basis was part of the mine Quality Control procedure, and results were used to plan extraction ratios for late stages of extraction at the mine.

\subsection{Progression of Ground Support Requirements}

Production performance is related to the CDS and this aids in estimating more realistic schedules. Another significant cost to newly seismically active and high stress mines is the escalation in ground support requirements with depth.

A common problem is that gradual changes in observed rockmass response and increasing levels of seismicity are dealt with reactively rather than proactively. The failure to plan for ground changes, means many mines employ low 
TABLE 2 BME Ground Support Selection Scale (G3S) ( $\sim 5 \mathrm{~m}$ x $5 \mathrm{~m}$ drives) - FOS refers to a CDS calibrated model

\begin{tabular}{|c|c|c|c|c|c|c|c|}
\hline Type & $\begin{array}{l}\text { Support } \\
\text { Component }\end{array}$ & Support & Comment & Example Application & $\begin{array}{l}\text { Drive } \\
\text { Convergence }\end{array}$ & $\begin{array}{l}\text { Modelled } \\
\text { Loss of } \\
\text { Confinement } \\
\end{array}$ & FOS \\
\hline 1 & $\begin{array}{l}B \\
C\end{array}$ & $\begin{array}{l}\text { High toughness (>1250J), 100-150 } \\
\text { mm fibrecrete } \\
\text { Mesh over fibrecrete } \\
\text { Cement or resin grouted "yielding" } \\
\text { bolts or debonded cable bolts } \\
\text { through fibrecrete and mesh } \\
\text { Second pass of fibrecrete after some } \\
\text { deformation } \\
\text { Variations: Straps as well as mesh } \\
\text { in seismic environments, mesh } \\
\text { reinforced shotcrete instead of } \\
\text { fibrecrete, Cable bolts in larger drives }\end{array}$ & $\begin{array}{l}\text { Steel fibres or special poly } \\
\text { fibres only. } 100 \mathrm{~mm} \text { monolithic } \\
\text { lining } \\
\text { Arc Welded Mesh } \\
\text { Bolt selection depends on drive } \\
\text { size, damage extent into wall } \\
\text { and other factors } \\
\text { This is not optional for this level } \\
\text { of deformation } \\
\text { Mesh reinforced shotcrete used } \\
\text { only so shotcrete can be batch } \\
\text { sprayed. Lagging shotcrete } \\
\text { behind the face is an inferior } \\
\text { option }\end{array}$ & $\begin{array}{l}\text { In drives subjected to } \\
\text { very high mining induced } \\
\text { deformations or in squeezing } \\
\text { ground. Damage to drive } \\
\text { surface approached }>1 \text { bolt } \\
\text { spacing deep (FOS }<0.7 \text { ) }\end{array}$ & $250-500 \mathrm{~mm}$ & $>20 \mathrm{mPa}$ & $<0.7$ \\
\hline 2 & C & $\begin{array}{l}\text { Moderate toughness (>800J),75-100 } \\
\text { mm thick fibrecrete } \\
\text { Mesh over fibrecrete may be required } \\
\text { if confinement loss is great or } \\
\text { deformation is uneven } \\
\text { Cement or resin grouted bolts or } \\
\text { mix of plain and bulbed cable bolts } \\
\text { through fibrecrete and mesh } \\
\text { Variations: Mesh reinforced shotcrete } \\
\text { instead of mesh over fibrcrete } \\
\text { where initial surface confinement is } \\
\text { less important i.e. no time related } \\
\text { degradation of surface conditions. } \\
\text { "Yielding" bolts or cable bolts where } \\
\text { seismicity or un-even deformations } \\
\text { are expected. }\end{array}$ & $\begin{array}{l}\text { Steel fibres or special poly } \\
\text { fibres only. } \\
\text { Arc welded mesh, required for } \\
\text { induced deformation. } \\
\text { Bolt selection depends on drive } \\
\text { size, damage extent into wall } \\
\text { and other factors. }\end{array}$ & $\begin{array}{l}\text { In larger drives subjected } \\
\text { to high mining induced } \\
\text { deformations, likely to induce } \\
\text { obvious, deep surface dete- } \\
\text { rioration. Damage to drive } \\
\text { surface less approaches } \\
1 \text { bolt spacing deep (FOS } \\
\text { approaches } 0.7-0.9 \text { ) }\end{array}$ & $100-300 \mathrm{~mm}$ & $>10 \mathrm{mPa}$ & $0.7-0.9$ \\
\hline 3 & $A$ & $\begin{array}{l}\text { Mesh OR fibrecrete (>800J), } 75 \mathrm{~mm} \\
\text { thick or mesh reinforced shotcrete } \\
\text { Cement or resin grouted dowels or } \\
\text { mix of plain and bulbed cable bolts } \\
\text { Variations: mesh straps or double } \\
\text { mesh instead of straps. Yielding or } \\
\text { debonded bolts }\end{array}$ & $\begin{array}{l}\text { Selected dependent upon } \\
\text { application process and initial } \\
\text { ground conditions } \\
\text { Bolt selection depends on drive } \\
\text { size, damage extent into wall } \\
\text { and other factors. } \\
\text { mesh straps or double mesh } \\
\text { when mesh is prone to some } \\
\text { limited bagging requiring reha- } \\
\text { bilitation (excessive bagging } \\
\text { would result in requirement for } \\
\text { category 2) }\end{array}$ & $\begin{array}{l}\text { In larger drives subjected to } \\
\text { moderate mining induced } \\
\text { deformations, likely to induce } \\
\text { obvious surface deterioration. } \\
\text { Damage to drive surface less } \\
\text { less than } 1 / 2 \text { bolt spacing } \\
\text { deep (FOS approaches } 0.9 \\
\text { to } 1.1 \text { ) }\end{array}$ & $50-150 \mathrm{~mm}$ & $>5 \mathrm{mPa}$ & $0.9-1.1$ \\
\hline 4 & $A$ & $\begin{array}{l}\text { Mesh OR fibrecrete (>800J), 50-75 } \\
\mathrm{mm} \text { thick } \\
\text { Cement or resin grouted dowels }\end{array}$ & $\begin{array}{l}\text { Selected dependent upon } \\
\text { application process and initial } \\
\text { ground conditions }\end{array}$ & $\begin{array}{l}\text { In larger drives in good } \\
\text { rockmass conditions, } \\
\text { subjected to minor mining } \\
\text { induced deformations, likely } \\
\text { to induce only infrequent } \\
\text { areas of deterioration, but } \\
\text { where blocks may be mobil- } \\
\text { ised by adjacent mining(FOS } \\
\text { approaches } 1.2 \text { to } 1.4 \text { ) }\end{array}$ & $<50-100 \mathrm{~mm}$ & $2.5-5 \mathrm{mPa}$ & $1.0-1.2$ \\
\hline 5 & $B$ & $\begin{array}{l}\text { Mesh (maybe fibrecrete in cycle) } \\
\text { Split sets }\end{array}$ & $\begin{array}{l}\text { Fibrecrete only if there is a } \\
\text { scheduling or other advantage }\end{array}$ & $\begin{array}{l}\text { In larger drives in good } \\
\text { rockmass conditions, } \\
\text { subjected to minor mining } \\
\text { induced deformations, likely } \\
\text { to induce only infrequent } \\
\text { areas of deterioration (FOS } \\
\text { approaches } 1.2 \text { to } 1.4 \text { ) }\end{array}$ & $0-50 \mathrm{~mm}$ & $2.5-5 \mathrm{mPa}$ & $1.2-1.4$ \\
\hline 6 & $A$ & Grouted bolts & Ongoing scaling required & $\begin{array}{l}\text { In larger drives in excellent } \\
\text { unjointed rockmass condi- } \\
\text { tions, never to be subjected } \\
\text { to excessive mining induced } \\
\text { deformations (FOS always } \\
\text { exceeds 1.4) }\end{array}$ & $0-25 \mathrm{~mm}$ & $<2.5 \mathrm{mPa}$ & $>1.4$ \\
\hline 7 & $A$ & Split sets & Ongoing scaling required & $\begin{array}{l}\text { In small drives in excellent, } \\
\text { unjointed rockmass condi- } \\
\text { tions, never to be subjected } \\
\text { to excessive mining induced } \\
\text { deformations (FOS always } \\
\text { exceeds 1.4) }\end{array}$ & $0-25 \mathrm{~mm}$ & $<2.5 \mathrm{mPa}$ & $>1.4$ \\
\hline
\end{tabular}




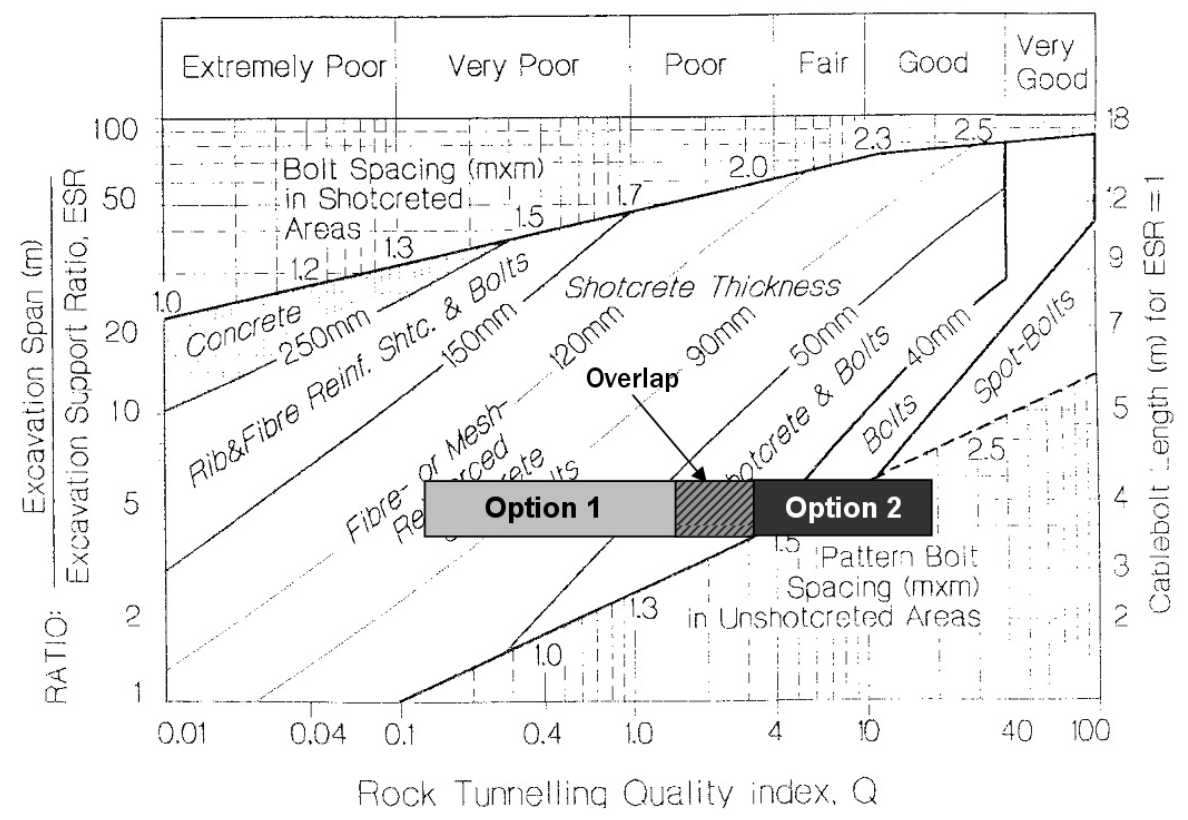

FIG. 11 Barton and Grimstad (1994) Q support guidelines (reproduced from Diederichs and Hutchinson, 1993) and the implied variation for two mine sequence options at an example mine

levels of primary support for too long, and then experience an extended period where damaged production areas are progressively treated with more and more rehabilitation.

Eventually, if conditions worsen, the mines make a stepchange from low levels of primary support, to extreme measures such as yielding support and thick, extra-tough fibrecrete. Sometimes these come too late and high rehabilitation costs, production delays and increased hazard levels are experienced.

A preferred management approach would be where ground support is gradually escalated to match developing seismic or stress hazards, but most ground support selection schemes do not lend themselves to gradual introduction of support types.

An example of the application of the $Q$ support guidelines (Barton and Grimstad, 1994) is shown in Figure 11. The scheme is widely applied by consultants and mine sites alike to estimate support levels in feasibility studies and early planning stages, or as a quantitative descriptor of ground conditions.

In the example, the range of conditions in production areas is indicated for two mining options. Changes in forecasts of induced stress result in widely disparate $S_{f}$ and support requirements. The clear delineation between the options shows an important feature - ground support performance for different mining options can potentially be assessed and provides an excellent argument for application of such a system.

Unfortunately, the descriptions of support are fairly broad, and small changes in $Q$ result in step changes in required support levels. Over the space of one or two panels in a steeply dipping West Australian mine, a change from spot bolting to shotcreting can be recommended. Blind adherence to the scheme would promote the reactive scenario for ground support management discussed above.

While not a replacement for ground support selection schemes, a ground support scale with a more gradual increase in support requirements from regime to regime is presented in Table 1. The scale is called the Ground Support Selection Scale (G3S).
Using the gradual progression of support detailed in the G3S, a stepped transition between shallow support and deep support can be planned. It is possible that different support types could be phased into a development contract, so that penalties for introduction of new support requirements can be avoided or reduced. The goal is that just enough ground support would be planned, minimising over-supporting and rehabilitation.

The regimes of ground support that the scale is based on are the typical support solutions used in the Australian hard rock mining industry and are familiar to contractors. All of the mines used to compile the scale have drive diameters in the range of 4.5-6 metres, use similar development techniques, and all have adopted high extraction ratio mining methods.

To account for the variation in hazards seen from mine to mine for similar damage levels, specific variations for seismic prone or higher deformation environments are suggested. Each variation would be selected to deal with particular local rock phenomena. The support components actually selected will vary depending on practical considerations such as available equipment.

As a rough guide for planning purposes only, the drive convergence seen at some mines successfully employing each support scheme has been estimated and plotted against each category in the table. This is a guide only as in each separate mine the ground reacted differently to the same estimated convergence. For example, in some mines the seismic activity was higher for a given level of closure, so implementation of support varied.

If a suitably calibrated non-linear model is available to model drive closure, the closure values might be used at early planning stages to estimate to what degree each of the regimes will be employed.

\subsubsection{Quantitative assessment of ground support progression?}

Although systems such as $Q$ are sometimes used semiquantitatively to assist in planning estimates, most ground support estimates in planning studies are based on experience and are opinion based judgements. If an opinion based judgement is used to employ the G3S, the engineer would 


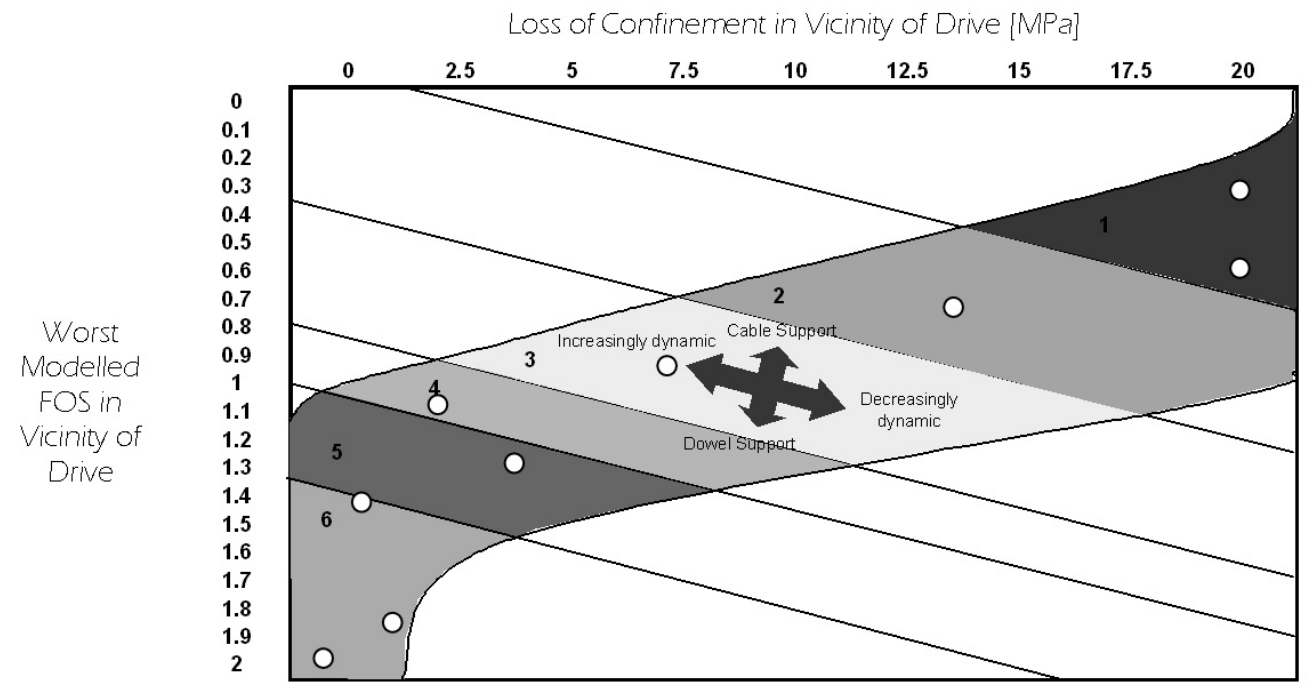

O Case Study Mine Data

FIG. 12 Comparison of numerical model results and typically applied measures from the G3S ( $\sim 5 \mathrm{~m} \times 5 \mathrm{~m}$ drives)

estimate the highest requirement at depth, and the lowest requirement for lower deformation areas, and interpolate in between depending on estimates of the effects of geometry, depth and geological factors, to determine where each new regime might need to be implemented.

To assist in planning quantitatively for the transition between required support levels in planning stages, it is proposed that the modelled damage and stress levels could be used to delineate between regimes of the G3S during planning stages. A first pass, preliminary and experimental attempt at this is presented in Figure 12.

To compile Figure 12, the support regime employed at eight mines was reviewed. In each mine, the support regimes actually employed had evolved in response to the conditions. These evolved solutions were compared to the modelled FOS in a typical area of application and the drop in confinement (change in $\sigma_{3}$ from the virgin condition). As the models were elastic BE models, multiple stages leading up to the current extraction geometry were reviewed to ensure the correct FOS was identified.

In all eight mines the FOS and stress estimates are based on brief review of the results of CDS calibrated models (FOS for moderate damage approximate 1.0), so it should be roughly valid to compare the results.

All mines had highly variable levels of stress related hazard and the correlation and application is still highly experimental, but there is some relation between the modelled results and the ground support that each mine has selectively applied.

It obviously isn't possible to reduce the entire ground support, seismic and drive performance at a mine to a single number, so some judgement in applying the technique is required. At best, the result should be seen as an experience based judgement, but in competition with dead reckoning, or as a first pass input and applied in conjunction with an ongoing continuous improvement program, the graph should have some application.

If the system is applied for planning at a mine, the elastic model should first be calibrated so that "moderate" damage as described in the CDS approximates an FOS of 1.

In practice, during the operational period at the mine, the time for implementation of one regime or another would be managed by the mines continuous improvement process, resulting in changes to the original plan. However, the inclusion of changes in the initial plan using the G3S and the CDS (or a system such as Q adapted for the purpose) would have meant that the process was proactive, rather than reactive.

\subsubsection{Further development}

The combination of the CDS and the G3S to estimate support requirements in a planning stage is experimental and needs further work.

The scheme needs to be applied and tested in a wider range of mining environments.

\section{CONCLUSIONS - RESILIENCE AND SUSTAINABILITY IN DESIGN}

Resilience and sustainability are the key requirements for any mining operation but they are difficult to achieve if actual geotechnical performance is not forecast or if the cost of adverse geotechnical conditions are not integrated into economic models.

Some simple concepts are presented here as a framework or methodology for site based engineers to plan gradual changes that might occur in highly stressed environments.

It is unlikely that applying a more rigorous framework to these estimations will result in an exact forecast of actual conditions or requirements, but the schemes may assist operations to be prepared for hazards, and to take advantage of opportunities when they do occur.

\section{REFERENCES}

Barton, N. and Grimstad, E. (1994) The Q system after 20 years of application in NMT Support Selection. Herausberger: Osterreichische Gesellschaft Fur Geomechanik.

Beck, D.A. and Brady, B.H.G. (2002) Evaluation and application of controlling parameters for seismic events in hard-rock mines. International Journal of Rock Mechanics and Mining Sciences. Editorial reference: 2002/002093.

Beck, D.A. and Sandy, M.P. (2003) Sequencing for high extraction in high stress West-Australian Mines. AusIMM Bulletin. June 2003.

Capes, G. (2003) Photograph of Very Significant Damage. Personal Collection.

Diederichs, M.S. and Hutchinson, D.J. (1993) Cablebolting in Underground Mines. BiTech Publishers Ltd, Canada.

Martin, C.D., Kaiser P.K. and McCreath, D.R. (1999) Hoek-Brown parameters for predicting the depth of brittle failure around tunnels. Can. Geotech. Jour., Vol 36, pp. 136-151.

Wiles, T.D. (2004) Map3d Manual. 